\section{Além do finito e do definido 1}

\section{RESUMO}

Este texto reflete sobre a vida e a obra de Edgar Morin, e toda sonoridade vivida sob o ritmo bioantropomitológico, tendo como impulso reelaborar a fábula "A cigarra e a formiga" em outro registro. Há muitas maneiras de montar a epifania, mantendo alguns elementos básicos e alterando a sua mensagem. Tenta recuperar algumas imagens vitais, adaptarse a elas e continuar-lhes o movimento, como um improviso declamatório da embolada. Pensa no mundo passado, presente e futuro e na missão dos intelectuais.

\section{ABSTRACT}

This is a text about the life and the work of Edgar Morin as well as a tentative of reformulation of the classsical fable of the dragonfly and the ant. It also thinks about the world in the past, present and future tense in relation to the mission of intelectuals.

\section{PALAVRAS-CHAVE (KEY WORDS)}

- Edgar Morin

- Conhecimento (Knowledge)

- Informação (Information)

\section{Margarida Maria Knobbe² UFRN}

Primeiro solo:

\section{EMBOLADA FABULAR}

"Não existe um verdadeiro término na análise mítica, nenhuma unidade secreta que se possa atingir ao final do trabalho de decomposição. Os temas se desdobram ao infinito. (...) Nem um pouco preocupado em partir ou chegar de modo definitivo, o pensamento mítico não efetua percursos completos: sempre resta algo a perfazer. Como os ritos, os mitos são intermináveis." (Claude Lévi-Strauss)

\section{A formiga, a cigarra e o sábio}

ERA UMA VEZ, numa civilização dominada pelos insetos, um formigueiro tão organizado, mas tão organizado, que a maioria dos outros formigueiros do mundo inteiro o invejavam e desejavam transformar-se à sua imagem e semelhança. Seu nome era Agimfor e ocupava alguns palmos de terra de um lugar chamado Aporeu.

Ali tudo parecia funcionar matematicamente. Cada habitante sabia exatamente qual a sua função, fixada pela casta à qual pertencia. As tarefas individuais eram cumpridas tão à risca e tão ritmicamente compassadas que os pedacinhos do todo pareciam formar um único organismo. Perfeito. Funcional e exato como uma máquina, por dentro e por fora.

A força que pairava sobre e entre os habitantes de Agimfor devia-se a um só lema: "Ordem é progresso". Obedientes, as formigas-indivíduos seguiam as normas às cegas. Era a garantia da própria sobrevivência. O que importava era só o trabalho conjunto e superespecializado de cortar, recortar, carregar, classificar, 
padronizar, alimentar as larvas e a rainha. Tudo igual, sempre. Os dias, as noites, os meses, os anos.

Como as operárias armazenavam comida suficiente durante o verão, no inverno a lida se circunscrevia ao interior da habitação comum: nos berçários, nos túneis embaixo da terra. Cavavam novos túneis, mantinham barreiras e garantiam a segurança da coletividade. Mas retinham as informações comunicando-as, economicamente, apenas à boca pequena. As palavras nunca eram desperdiçadas.

O passado era a herança do presente ativo e do futuro de ainda mais atividade durante a vida ou de esquecimento com a morte. E a morte de uma formiga-indivíduo não afetava em nada a vida global do formigueiro. Sem choro nem velas! Existia um exército de outras formiguinhas iguaizinhas para realizar o mesmo trabalho do mecanismo gasto, desaparecido. O todo era mais importante e maior do que as partes.

"A técnica e a burocracia propagam uma inumanidade congelada, mecânica, desintegrando por suas quan-tificações as realidades vividas dos seres de carne, de sangue e de alma. A especialização e a compartimentali-zação destroem o sentido de responsabilidade. Cresce, assim, a crueldade por indiferença, desatenção e cegueira." (Morin, 1997: 273)

$\mathrm{Na}$ geografia daquele tempo, a Terra era bem dividida. No entanto, as operárias de Agimfor mal se davam conta. Fora dali, os outros animais se agrupavam por espécie. Cada qual tentava viver à sua moda, dentro dos limites territoriais impostos pelas rainhas-formigas, dominadoras do mundo.

Os estrangeiros, entre as próprias formigas, eram raríssimos. Outros animais no formigueiro, então, estava fora de cogitação. A não ser quando mortos, com a carne em decomposição, para servir de alimento. As fronteiras entre os formigueiros e as demais áreas estavam milimetricamente definidas e bem guardadas.

De vez em quando, durante o trabalho diário de sair à cata de provisões, ouvia-se um canto. Ninguém parava para apreciá-lo. Quando a ousadia da voz chegava mais próxima, a formiga-capataz fazia transmitir, uma a uma, para todas as operárias em fila simétrica, uma velha história já tão repetida:

"- Cuidado! Não dêem ouvidos à exibida cigarra! Essa, que quando larva não encontramos para nosso suprimento, com certeza estará em nossos depósitos assim que acabe o verão ${ }^{3}$ ! Lembrem-se: trabalhamos, logo existimos."

"Tanto nas ciências naturais como nas ciências humanas, o conhecimento mergulha na ideologia, com ortodoxias, alegações gratuitas e rejeições cruéis logo que marginais e desviantes se exprimem. Ao mesmo tempo, o espírito disciplinar leva a uma comparti-mentalização da inteligência. (...) Enfim, o instinto territorial, muito desenvolvido no mundo animal, é despertado com ferocidade no especialista. Ele se considera como o 'proprietário' do domínio (físico, ético, cultural), cujo centro ele acredita ocupar, e ataca os intrusos com lança-chamas." (Morin, 1997: 214)

Logo, logo, esse modelo perfeito de Agimfor foi alardeado aos quatro cantos do mundo, pelo ar, pelo mar e pelos subterrâneos, por outros seres vivos que o admiravam a distância. E muitas rainhas de outros coletivos formigantes começaram a enviar mensageiros solicitando consultoria às autoridades agimforianas.

Foi um verdadeiro reboliço. Depois de tantos - "Alto lá! É proibido aproximar-se", a rainha de Agimfor resolveu, afinal, saber o 
que estava se passando. Muitos trofolaxes boca a boca após, o conselho real decidiu que essa era uma boa oportunidade para Agimfor expandir-se. O plano era enviar suas melhores trabalhadoras-intelectuais para doutrinar os outros formigueiros, colonizando-os em benefício do reino de Agimfor.

O processo de seleção foi dificílimo. A maioria das operárias tremia de medo do desconhecido. Umas acabaram aceitando a missão porque era uma ordem. Já para outras escolhidas, a curiosidade sobre os novos mundos e a oportunidade de desbravá-los eram maiores e mais instigantes do que o medo e a obrigação.

Uma das voluntárias curiosas e excitadas era Torebla, jovem e eficiente estudiosa dos meios de conseguir mais disposição e força para os corpos formigais. Animada com a perspectiva de afastar-se um pouco de seu laboratório experimental, Torebla deu-se conta de que, além de obediente, também começava a descobrirse uma formiga que tinha desejos, e sonhos. Imaginou até encontrar-se com uma daquelas tão malfaladas cigarras, cujas vozes havia escutado de relance e cujos corpos conhecia somente inertes, mortos. A perspectiva a fez descobrir outra sensação: o prazer.

"Foi o excesso de mentira, de besteira, de crueldade que quebrou, ao mesmo tempo, a racionalidade e a mora-lidade do sistema em minha consciência." (Morin, 1997: 75)

Para salvaguardar sua integridade, Torebla engoliu com força a nova química que lhe subia à boca e mostrou indiferença quando the indicaram o caminho. O mais longo de todos, rumo ao formigueiro mais distante, lá pelas terras de Carifa, chamado Gonco.

A viagem foi difícil, mas Torebla não teve tempo para reclamar. Eram tantas as surpresas e novidades para ver, ouvir, sentir e compreender... Também não importava o silêncio respeitoso de seu guia, a formiga embaixadora do Gonco. Ainda mais depois que a diplomata lhe ofereceu de presente uma ferramenta esquisita que servia para copiar sons.

Torebla aprendeu depressa a manusear a caixa com umas pecinhas brancas presas apenas por uma das pontas e enfileiradas lado a lado. Experimentando aqui e ali, tentava imitar todos os cantos e linguagens que ouvia durante o percurso. Nos momentos de descanso - nem as formigas são de ferro! - a desajeitada já conseguia até inventar novas harmonias. A primeira seqüência, é claro, inspirada no canto da maldita cigarra, que, na verdade, para Torebla, nunca foi tão maldita assim, mesmo quando a estridência do som parecia cutucar alguma coisa bem lá dentro de sua cabecinha e de seu coraçãozinho de formiga.

“(..) o ser humano produz duas linguagens a partir de sua língua: uma, racional, empírica, prática, técnica; outra, simbólica, mítica, mágica. (...) Essas duas linguagens podem ser justapostas ou misturadas, podem ser separadas, opostas, e a cada uma delas correspondem dois estados: o prosaico e o poético."(Morin, 1998: 35 $-36)$

Passaram-se muitos dias e muitas noites; muitos sóis e muitas luas; muita areia e muita água... Torebla já não se parecia com a mesma formiga que havia partido de Agimfor. Uma metamorfose interessante começara a se processar. De seu formigueiro, lembrava-se como de outra vida em outro tempo. Nunca antes se dera conta de que havia um tempo diferente daquele que respirava em seu laboratório... Certo e exato como 2 e 2 são 4. A aventureira, agora, começava a duvidar até mesmo dessa e de outras tantas certezas. Afinal, o que conhecia antes, comparado com a enorme variedade de vida desses novos caminhos? 
"Quem sou eu? Minha singularidade dissolve-se assim que a examino e, finalmente, convenço-me que minha singularidade vem de uma ausência de singularidade. (...) Minha singularidade é a de ter querido unir o diverso, sparsa colligo, e de ter feito minha obra baseada neste princípio. (...) Religar, religar. Tornouse, não a palavra-chave, mas a Idéia-mãe. O conhecimento que religa é o conhecimento complexo. A ética que religa é a ética fraternal, a política que religa é a política que sabe que a solidariedade é vital para o desenvolvimento da complexidade social." (Morin, 1997: 253, 256, 260)

Preparada para mais desafios, com a cabeça repleta de perguntas sem respostas, Torebla chegou ao Gonco. Apesar do preparo, espantou-se. As formigas gonquianas receberam a emissária agimforiana com uma FESTA! Torebla jamais havia sequer imaginado o que era uma festa. Nem pensar em Agimfor... perda de tempo e de energia para o trabalho!

Além disso, notou que o passo disciplinado e militar das operárias agimforianas era sem graça e duro se comparado ao gingado diversificado dessas formigas gonquianas.

"-Aqui não existem regras para andar!", exclamou, embasbacada. Cada um se movia de acordo com o som que lhe ia, inaudível, na cabeça ou embalado pelos tons da vida à sua volta.

Passado o primeiro impacto da recepção acalorada, Torebla pôs-se mãos à obra. Só que a sua missão não seria mais a mesma. Decidiu ensinar, sim, o que sabia, mas não doutrinar ninguém; muito menos em benefício de seu longínquo reino Agimfor que - agora percebia! - tinha muitos defeitos.

Elaborou um plano de trabalho e o apresentou às autoridades gonquianas.
Já meio contaminada pela ausência das burrocratas regras de Agimfor, para conseguir maior atenção de seus ouvintes, Torebla acompanhou o seu próprio discurso com a maquininha de sons.

Afinando bem a garganta, em resumo, propôs o seguinte:

“DÓDÓ, RÉ...RÉ.RÉ. Pretendo viver por tempo indeterminado em Gonco, auxiliando o formigueiro no que for possível."

"MI, FÁFÁ... Me disponho a ensinar o que acho que sei (o segredo da organização de Agimfor; os truques de suas tarefas diárias superespeci alizadas) e aprender o que não sei (outras especialidades, incluindo aquelas banidas de Agimfor: a música e o contato com outras formas de vida)."

"SOL, SOOOOLLLLLL....LÁ. Cada habitante do Gonco tem que continuar a pensar sozinho, escolher as suas próprias atividades e sentir-se responsável pelo bem-estar de todos, sem se restringir a esse montinho de terra."

"SISISISISISI.SISISISISI... Enfim, creio que podemos reinventar um sistema de formigueiro aberto a novas experiências."

Com alguns tropeços, inevitáveis num ambiente tão aberto e democrático, a aceitação da proposta de Torebla resultou em modificações profundas no formigueiro. $\mathrm{Na}$ verdade, depois de um tempo, já não se podia nem classificá-lo como um formigueiro. Era um multigueiro.

É raro que os intelectuais pratiquem o que deveria ter sido desenvolvido normalmente por sua cultura: a atenção ao discurso do outro, a capacidade de ouvir um argumento sem defor-má-lo. (...) É preciso reconhecer o direito de palavra aos que dividem e negam, isto é, ao diabo, já que este é, ao mesmo tempo, o espírito que nega e a força que divide.

$\mathrm{O}$ intelectual tem, portanto, a tarefa 
mais difícil que jamais foi apresentada na história da cultura: resistir a todas as forças que prejudicam a reflexão e ser capaz de trazer sua reflexão sobre as contribuições capitais das ciências contemporâneas a fim de tentar pensar o mundo, a vida, o ser humano e a sociedade.

(Morin, 1997: 218 - 219)

De cada animal, planta, pedra, gota de líquido ou sopro de ar, o Gonco inteiro aprendeu algo. Por exemplo, o elefante ensinou a paciência; o leão, a coragem; a águia, a visão de novos horizontes; a flor mostrou a ternura... O amor expandiu-se pelo canto dos pássaros. Mas a voz da consciência, melódica, embora crítica, ensinou-lhes a velha cigarra.

Não era um paraíso perfeito porque todos precisavam comer. Como não caía maná do céu, os animais continuaram alimentando-se uns dos outros. Só que à anterior caça predatória dos carnívoros, seguiu-se um respeito mútuo entre devorador e devorado. Uns sabiam que dependiam dos outros e ninguém saía comendo além do necessário para a própria sobrevivência.

Porém, entre formigas e cigarras foi possível um acordo. As cigarras passaram a alimentar as formigas com o líquido açucarado que produziam a partir da seiva das plantas. Nenhuma formiga precisava acumular restos de animais mortos em suas despensas - muito menos comer cigarras!

A ordem continuou a importar para Torebla, mas sem ser obsessiva. E todo mundo aprendeu a nova ordem. O trabalho, necessário, foi reconfigurado para não ser opressivo, à escolha de cada colaborador. As metas, agora, eram conservar as riquezas naturais, conviver com todos os seres e buscar a felicidade.

De vez em quando surgia um nhenhenhém. O professor que não conseguia responder tudo o que a curiosidade dos alunos reclamava... O escrevente que, às vezes, inventava palavras que só os outros escreventes entendiam e, na verdade, não significavam nada... Os herdeiros da rainha que se sentiam lesados em sua majestade.. Só que isso tudo - e muito mais - era resolvido por todos, no centro da praça formigal. Até sobraram mais palavras para serem transmitidas boca a boca... Mas essas eram, em sua maioria, declarações amorosas, manifestações de afeto...

As únicas resistências estão nas forças de cooperação, comunicação, compreensão, amizade, comunidade e amor, com a condição que sejam acompanhadas de perspicácia e de inteligência, cuja ausência pode favorecer as forças da crueldade... (...) Resistir, resistir em primeiro lugar a nós mesmos, a nossa indiferença e a nossa desatenção, a nossa preguiça e ao nosso desânimo, a nossas vis pulsões e mesquinhas obsessões. (...) A busca do esforço cósmico desesperado que, no ser humano, toma a forma de uma resistência à crueldade do mundo é o que eu chamaria de esperança. (Morin, 1997: 273 - 274)

Seres mais completos, por dentro e por fora, a soma dos habitantes do Gonco tornou-se maior do que todo o Gonco, idéia que deu origem a uma nova matemática. Ao laço de solidariedade que pairava sobre e entre os moradores da área, acrescentavam-se a toda hora a energia e as qualidades individuais.

A convivência próxima entre formigas e cigarras revolucionou suas naturezas. As mães teciam juntas os casulos das ninfas cigarras e os berços das formigasbebês. Depois de certo tempo, começaram a nascer formigas cantantes, cigarras dançarinas...

A linguagem acompanhou a metamorfose. Tanto formigas quanto cigarras passaram a comunicar-se unindo 
as químicas trofoláticas formigais ao retumbar físico das membranas cigarrais. Sim, porque as formigas também criaram membranas, que produziam sons timbalando no abdômen, e asas. Gostavam, de vez em quando, de voar até as árvores onde as cigarras moravam para conversar, discutir uma idéia, ensaiar uma nova melodia ou, simplesmente, para espairecer.

"Trazemos em nós personalidades potenciais que acontecimentos ou acidentes podem desencadear e atualizar. (Morin, 1997: 84)

Assim como a transformação geral, Torebla já não era mais uma simples formiga especializada e eficiente. Após certo período de trabalho, reunia-se com - grupo para cantar, tocar sua máquina de sons e contar histórias. Passou a ser chamada de sábio, por suas habilidades de formiga, consciência de cigarra e um tiquinho de cada ser com o qual convivia, aprimorando-se no conhecimento dos corpos e das almas.

(...) creio que as grandes linhas da sabedoria se encontram na vontade de assumir as dialógicas humanas, que podem ser resumidas na dialógica sapiens-demens e na dialógica prosapoesia. (Morin, 1998: 66)

Passados alguns verões, o balanço de todas as viagens realizadas pelas formigas agimforianas registrou perdas e ganhos, dependendo do ponto de vista, é claro. Nem todas as embaixadoras de Agimfor retornaram na data combinada. Entre as que obtiveram sucesso, as emissárias cumpridoras de ordens juraram ter completado suas obrigações, entupindo os depósitos de Agimfor de especiarias até então desconhecidas nas terras de Aporeu. Outras, chegaram praticamente sem carga, mas elas próprias muito, muito diferentes.

Por causa dessas diferenças, o sistema agimforiano nunca foi mais o mesmo. Negando-se a reformar suas regras, aos poucos, Agimfor foi diminuindo, dimunindo, até desaparecer completamente. Algumas formigas dissidentes, influenciadas por aquelas mensageiras que retornaram diferentes, geraram outros formigueiros independentes.

Vez por outra, recebiam notícias de um formigueiro chamado Gonco, terra longínqua para a qual Torebla saiu como formiga, aprendeu o canto da cigarra, e metamorfoseou-se em sábio.

"O que percebo, hoje, é que as perturbações mentais suscitadas pelos abalos sísmicos do século, as aquisições contínuas de minha curiosidade nômade, meu modo de pensar através do jogo de idéias contrárias, meu interesse não apenas pelos dados em-píricos e pelo acontecimento, mas também pelas idéias e pelos problemas antropológicos, além de meu temor obsessivo de errar (...), tudo isto, de maneira convergente, vitalizou um processo assimilador/interrogador contínuo, com fases eruptivas que foram verdadeiramente reorganizadoras." (Morin, 1997: 202)

Milhões de anos depois, uma outra espécie animal, descendente dos macacos, começou a julgar-se dona da Terra. Nas lendas que esses seres transmitiam de geração para geração, as formigas e as cigarras eram, muitas vezes, as personagens principais.

Contavam, por exemplo, que na origem do mundo, quando houve o casamento sagrado entre o Céu e a Terra, o sexo da terra era um formigueiro. De sexo, o formigueiro transformou-se, posteriormente, em uma boca de onde saíram a palavra e a técnica da tecelagem, elementos fundamentais que as formigas ensinaram aos homens ${ }^{4}$.

Já à voz das cigarras foi atribuído o 
poder do rejuvenescimento, inspirando as coisas divinas e as artes.

Mas essa é outra longa história...

"Acredito que hoje seja necessário dizer: sejamos irmãos porque estamos perdidos num planeta suburbano, de um sol suburbano, de uma galáxia periférica, de um mundo desprovido de centro. Mesmo assim, possuímos plantas, pássaros, flores, assim como a diversidade de vida, as possibilidades do espírito humano. Doravante, aqui residirão nosso único fundamento e nosso único recurso possível.

A descoberta de nossa situação de perdição num gigantesco cosmos adveio das descobertas da astrofísica. Isto significa que, atualmente, é possível um diálogo entre ciência e poesia, e isso porque a ciência nos revela um universo fabulosamente poético ao redescobrir problemas filosóficos capitais: $O$ que é o homem? Qual é o seu lugar? Qual é o seu destino? O que pode se esperar dele?" (Morin, 1998: $41-42$ )

Segundo solo:

\section{PEÇA ININTERRUPTA}

"- O que é isto, Filha da Lua? Um grão de areia, respondeu ela.

- É tudo o que resta do meu reino sem fronteiras. Ofereço-o a você. (...)

- Olhe, Filha da Lua! murmurou ele. Começa a brilhar!

- E agora, está vendo?, começa a sair do grão de areia uma chamazinha minúscula. É uma semente! É uma sementinha brilhante que começa a germinar!." (Michael Ende)

"Hoje não se trata de soçobrar no apocaliptismo e no milenarismo, tratase de ver que estamos, talvez, no fim de um certo tempo, e, esperemos, no começo de tempos novos." (Edgar Morin)
Como na fórmula complexa da antropopolítica proposta por Edgar Morin, que se exprime pela junção: "pensar global/ agir local" e "pensar local/agir global", os intelectuais têm uma missão planetária, a partir de uma missão individual: o autodidatismo, para despertar outras potencialidades.

Seja como cientista, professor, jornalista, poeta, músico, artista ou escritor, têm também a missão de serem portadores e comunicadores de sentido. As funções determinadas são irrelevantes, desde que somos todos passageiros/artesãos - com iguais direitos e deveres - na mesma minúscula nave errante, vagando pela marginal Via Láctea.

Concordo que a tomada de consciência dessa Terra-Pátria pode por si mesma nos transformar em cigarras, em estado poético, porque a relação com a Terra é estética e, mais ainda, amorosa, às vezes extática.

Como

não

vacilar de êxtase quando uma enorme lua surge com assombro no horizonte rodeada por sua corte de nuvens e estrelas? Ou quando captamos o brilho de uma semente germinando? Entretanto, infelizmente, o êxtase é quase sempre substituído pela defesa do "eu" e do "meu". Em lugar de olhar a lua e a semente, vemos apenas os diferentes dedos apontados para elas, porque acreditamos que o "nosso dedo" é o único verdadeiro.

Ao mesmo tempo, não é só a fusão de cada corpo/espírito ao corpo/espírito geral do mundo que nos embala. Mas também a concentração do tosco, do fosco e do triste; dos fantasmas humanos, animais, vegetais e minerais. Sangue, dor, espinhos e espirros jorram sob o belo. Espelhos tridimensionais se erigem, monstros, antagônicos: a dimensão de ser corpo (formiga), a dimensão de ser alma (cigarra) e a dimensão de ser na realidade obtusa mais de um, anulando a aparência de finos cristais da capa das coisas.

Um estado poético permanente 
cansaria de si próprio ou se tornaria selvagem se fosse ininterrupto. E tenderia a ressuscitar as ilusões da salvação terrestre. Estamos mesmo condenados à complementaridade e à alternância poesia/ prosa, à perdição entre gozo e sofrimento, repressão e criatividade, linguagem trofolática e linguagem percussionista...

A criatividade, por seu turno, nasce da comunhão entre a nossa esfera racional e a nossa esfera emotiva. Porém, a exacerbação do racionalismo contribui para que três desvalores de ontem - relegados às profundezas ctônicas - ressurjam hoje como fundamentais: subjetividade, estética e emoção.

A dose certa de cada elemento depende dos sujeitos e suas circunstâncias. Cada intelectual, sob o ponto de vista complexo, tem que fazer o seu caminho durante a própria caminhada, cerzindo o tecido esgarçado do presente e os rasgos disciplinares. Mas há um calçamento básico: os poderes técnicos, o pensamento, a consciência devem ser destinados, não a dominar, mas a arrumar, melhorar, compreender e tentar fazer-se compreender.

\section{Uma das contratendências} que visualizo manifesta-se nessas resistências de vida de alguns pensadores - professores, cientistas, jornalistas, escritores, artistas - que podem contaminar áreas mais extensas do formigueiro. Microtecidos ainda isolados, mas com possibilidades de unir-se como os sons de uma orquestra no sentido unitas multiplex. Sua matéria-prima é composta tanto por trofolaxes ${ }^{5}$ quanto pela vibração percussionista de asas libertas de enxúvias 6 .

Todos os sons são diferentes. No jogo da complexidade social, é no processo da língua que os semitons distintos se encarregam de interpretar o mesmo fonema, os sentimentos, os atos, numa escala cromática. A seqüência de interações é infinita, fazendo mudar o sentido e criando universos de significação.
Há sempre um virtual reservatório de possibilidades.

Contra as monoculturas, esses multitons surgem do enamoramento e da cópula entre as idéias, permitidas pelo chamamento de outra idéia-matriz: o canto de atração sexual da cigarra ${ }^{7}$. Na excitação das idéias simultâneas, não há domínio de uma sobre as outras idéias seminais, nem a morte de nenhuma delas durante o processo sexual e de gestação de novos indivíduos-idéias. Além disso, as ninfas estão envolvidas por uma pedagogia da imaginação, são autônomas para construir sua vida e continuar a espécie, acasalandose e gerando a confluência e o entrechoque de outra multiplicidade de idéias, maneiras de pensar, estilos de expressão.

Com relação à formiga, ao contrário. A maioria é composta por informações trofoláticas emitidas por clones estéreis. Poucas chegam a acasalar-se. Quando isso acontece, um dos pares morre e os ovos-informações servem para garantir a repetição e a conformidade. Não há cópula de idéias; há imposição de informações utilitárias e funcionalistas.

O conhecimento compõe-se de idéias e informações, é verdade. Mas o conhecimento é organizador; a informação se apresenta sob a forma de bits. O importante não são as informações, mas a operação computante que as trata. A computação viva não se reduz à informação e comporta sempre um caráter cognitivo.

É essa dimensão computacional de todos os seres vivos que possibilita ao homo sapiens-demens reverter as informações estéreis em inquietas idéias animadas pela convivialidade. Dos subterrâneos infrapolíticos, infra-sociais e infrapsíquicos estão surgindo algumas combinações dessa arte transformadora: algumas ninfas da solidariedade (contra a atomização e a compartimentalização); da revitalização (contra a anonimização); da convivência (contra a degradação da qualidade de vida) e da moralização (contra a irresponsabilidade e o egocentrismo). 
E a arte consiste na interseção das mensagens e em descobrir dispositivos que permitam às formigas surdasmudas escutarem o seu próprio canto de criatividade cósmica. Todos os seres comportam dois seres: o de repouso e o de resistência. Os tempos ritmados lançam a percussão da resistência sobre o repouso, transcendendo-o, gerando energia dinâmica e viva, infundindo as virtudes de clareza e as forças de sonho.

Com o domínio das forças tecnoeconômicas nos meios de comunicação; das tesouras redutoras nas áreas do conhecimento e suas estruturas acadêmicas, o intelectual precisa munir-se de táticas de guerrilha. Descobrir nichos ou maneiras alternativas de disseminação das idéias. Mais uma vez, não há modelos. É a própria pulsão interior em defesa da polifonia e da polissemia que poderá apontar os atalhos pelos quais a árvore do conhecimento poderá unir-se à árvore da vida, alimentando outras ninfas ${ }^{8}$. Se as informações trofoláticas servem para transmitir conteúdos de conformidade e exclusão, podem também carregar líquidos seminais de idéias com outro sentido.

Essas ninfas irão sobreviver? Pode ser que sim.... Pode ser que não... É difícil conhecer além do finito e do definido. É impossível saber senão por meio da linguagem... $O$ que não se distinguiu nem denominou não pode ser ainda conhecido... Porém, da mesma forma que não podemos pegar o fogo, o fogo dessa nova consciência caosmica pode pegar-nos e apoderar-se de nós...

Assim como a lógica do pensamento transmitido pela palavra está longe do equilíbrio, as novas realidades são como um vento que impele com uma série de rajadas e abalos. Mas não basta deixarse levar pela direção do ar. É preciso criar imagens e palavras capazes de automovimento... Portanto, o nome intelectual, gasto e reduzido, precisa apoderar-se dessas novas forças de criação para renascer e reinventar outras possibilidades de vida.

Do lado oposto, há as forças da amplitude que dispersa e da retórica vazia, onde a linguagem não quer dizer quase nada; serve simplesmente para embasbacar os ingênuos, os ignorantes. Nessa nossa "era da informação", a humanidade está afogada num mar de palavras. Assim como a ciência médica atual volta sua atenção para a iatrogenia - a alteração patológica provocada no paciente pela ação do próprio médico ou pelo tratamento por ele prescrito -, os intelectuais precisam de uma ecologia do discurso; estabelecer estratégias cautelosas com relação às palavras/ações iatrogênicas.

No esforço para dar conta do aspecto sensível das coisas, há que considerar que não há exatidão absoluta. Depois de lançadas ao mar das línguas, as palavras tornam-se narrativas tentaculares fundidas na imensidão das mentes. Como monstrosmestres, tendem a apoderar-se do que se pretendia que designassem, manufaturando realidades indesejadas.

Em outro pólo, são transmissoras de um lastro de consciência, operam como o Thitonus $^{9}$ imortal que definhou fisicamente até restar apenas sua aguda voz. Não era ele. Mas era a "sua" voz, ainda a "sua" consciência. De outra forma, hitonus revela que se superar como intelectual é transcender não só as cadeias disciplinares, mas a própria imagem, o orgulho, a presunção, o status. Estar entre formigas sem se render às regras emudecedoras do formigueiro. Trazer a alma na garganta, como os tupis-guaranis, enxergando cada outro ser com um tom da grande música cósmica. Para o melhor e para o pior, sem ser necessário enforcarse.

Sonhando novos mundos, não podemos esperar nada do mundo, pois é o mundo que espera tudo de nós. Os principais fatos portadores de futuro não chegam prontos da fábrica nem estão determinados pelos genes. O devir do planeta, da natureza, da cultura, dos 
saberes, da educação, da academia, da comunicação, da imprensa, dos livros... está sendo forjado por nós à nossa imagem e semelhança, enquanto nos forja à sua imagem e semelhança...

É assim. Contudo, no fundo confuso da minha sensibilidade fatal, nego às minhas idéias do desconhecido a cor das noções do conhecido.

Debaixo do silêncio das estrelas, busco a companhia de Fernando Pessoa que, nesses momentos, se esconde atrás da porta para que a realidade, quando entre, não o veja. Peço-lhe que me ensine a pregar sustos na possibilidade.

Desligo de mim os dois tédios que me apertam - o tédio de poder viver só o real, e o tédio de poder conceber só o possível. E espreito a vida, espiral do nada e do tudo, infinitamente ansiosa pelo que ainda não há, como formigas cantoras e cigarras dançarinas...

Depois dessa viagem - da qual a narrativa capta poucas paisagens e solavancos -, alguma coisa ficou diferente.

A fenda no espaço do formigueiro não volta a se fechar. Não posso e não quero defender-me quanto a isso. Nada será como antes.

Sinto-me parte do espelho daquela 'Peça ininterrupta' descrita por Michael Ende (1984: 43-45). E entre os seus personagens - trajando roupas de saltimbancos de um desbotado multicolorido e aventureiro - que percorrem o mundo composto somente por fragmentos, buscando a palavra perdida, através da qual tudo se relacionava com tudo:

- De onde viemos? Da montanha do céu.

- O que fazíamos lá? Cada um de nós situava-se em um cume e gritávamos as palavras uns para os outros. Era uma peça para o Sol, a Lua e as estrelas, encenada sem cessar porque conservava o mundo unido. Um dia houve uma desgraça: notamos que nos faltava uma palavra. Ninguém a havia roubado, nós tampouco a esqueceremos. Ela simplesmente não estava mais lá... Desde então, estamos viajando para tentar reencontrá-la.

- E quem ou o que nos conduz? A palavra .

\section{Notas}

1 Fragmento da dissertação de mestrado em Ciências Sociais intitulada "Além do finito e do definido - Os intelectuais sob os ecos da fábula A cigarra e a formiga" (UFRN/2000).

2 Jornalista, mestre em Ciências Sociais (UFRN), pesquisadora do Grupo de Estudos da Complexidade - Grecom/UFRN.

30 naturalista francês Jean-Henri Fabre descobriu, por volta de 1870 , que a cigarra, que apenas se alimenta da seiva das plantas, serve ela própria de alimento para a formiga, consumidora de despojos animais.

4 Mito de fundação das tribos dogon e bambara, em Mali.

5 A linguagem das formigas é um intercâmbio químico contínuo chamado trofolaxes.

6 É a "camisa" que veste a ninfa da cigarra, abandonada depois da metamorfose.

7 Membranas nos lados do abdômen da cigarra produzem seu "canto" de atração sexual.

8 Cigarras jovens, antes da metamorfose, fechadas em seus casulos, sugam a seiva das raízes das árvores.

9 Mito grego sobre a imortalidade da cigarra. Bonito e jovem, Tithonus recebeu a dádiva da vida eterna de sua amante, a deusa da alvorada. A benesse divina, porém, não acabou com 0 inexorável avanço da idade. Com 0 tempo, Thitonus sofre uma metamorfose paradoxal: vai ficando cada vez mais velho e menor, até restar apenas a sua aguda voz, ou se tornar cigarra.

\section{Referências}

ENDE, Michael. 0 espelho no espelho: Um labirinto. São Paulo: Marco Zero/Círculo do Livro, 1984. 
MORIN, Edgar. Meus demônios. Rio de Janeiro: Bertrand Brasil, 1997.

Amor, Poesia, Sabedoria. Rio de Janeiro: Bertrand Brasil, 1998. 